\title{
Usability Analysis of Touch Screen for Ground Operators
}

\author{
Jungwan Hong1, Seungju Baek1, Heesoo Jung1, Suhwan Kim², Yongjin (James) Kwon ${ }^{*}$ \\ ${ }^{1}$ Department of Industrial Engineering, Ajou University, Suwon, South Korea \\ ${ }^{2} 1^{\text {st }}$ Division, $3^{\text {rd }}$ Department, Agency for Defense Development, Daejeon, South Korea \\ Email: *yk73@ajou.ac.kr
}

Received October 2015

\begin{abstract}
The importance of the aircraft is increasing gradually; among them it may be called Ground Control Station (GCS) receiving the highest expectations. In aspect of operation, operator's workload and working speed are one of the most important factors. Thus, we need to compare Touch mode and Non Touch mode in order to improve workload and working speed. In this paper, we analyzed the differences of Touch mode and Non Touch mode about workload, working speed in operation of aircraft. Through NASA-TLX and Measured working time, quantified data were collected and an analysis of variance (ANOVA) was performed. According to experimental result, working speed and workload according to input mode showed significant difference. In ground operation, Touch mode is better than Non Touch mode about working speed and workload. In the Touch mode, the optimal value of lower display angle was selected as $60^{\circ}$ angle.
\end{abstract}

\section{Keywords}

Touch Screen, Work Load, Ground Operator, Working Time, NASA-TLX, Ground Control Station

\section{Introduction}

The importance of the aircraft is increasing gradually, among them it may be called anti-air ground control station (GCS) are receiving the highest expectations. This can be regarded as worldwide trend. A GCS is defined as a "powered, aerial vehicle that does not carry a human operator, uses aerodynamic forces to provide vehicle lift, can fly autonomously or be piloted remotely, can be expendable or recoverable, and can carry a lethal or nonlethal payload". The biggest advantage of the GCS is people do not ride with no loss of life can do long-term mission. Also, ground control center has undergone a process of change and evolve over time. As time goes on, in order to maximize the performance of the battlefield situation, a study was conducted for each of the elements such as chairs, consoles, pedals. So ground control center has been evolving in the direction of improvement for the convenience and usability.

However, research on the touch screen usability is likely to not actively make. In the future, the touch screen is considered important to maximize the ability to operation of GCS. In operation as a GCS, it is necessary to

${ }^{*}$ Corresponding author. 
compare the performance of mouse and touch screen. Therefore, in this study, we measured the response time, workload in operating GCS simulator. And we analyzed the results shown by measurements.

\section{Related Study}

\subsection{NASA-TLX Analysis Method}

The NASA Task Load Index (NASA-TLX) is a widely-used, subjective, multidimensional assessment tool that rates perceived workload in order to assess a task (see Table 1) [1]. Through various industrial accidents and disasters, Workload has been found as one of the factors that have the greatest impact on the safety of the system. So in order to prevent the workload reduction, a number of studies were carried out. As a result, it was found that the main cause of Workload reduction is the complexity of the task. While operators are performing complex task, operators will experience a significant amount of the cognitive load [2]. Due to the complex task, if required cognitive load exceed operations ability, rapid task ability will occur [3]. This fact is supporting that assessing and managing task difficulty will prevent accident caused by task load decrease. The most effective method of assessing task ability is giving direct question to the operator. Therefore, various question investigations to assessing task ability were developed, such as NASA-TLX (task load index), Cooper-Harper scale, SWAT (subjective workload assessment technique) are known [4]. Of these, the most stable subjective task difficulty assessing method up to now is NASA-TLX Method [5].

NASA-TLX is configured to be able to quantify the degree of difficulty through the entire. There is a description for each of these subscales that the subject should read before rating. They are rated for each task within a 100 -points range with 5-point steps. These ratings are then combined to the task load index. Providing descriptions for each measurement can be found to help participants answer accurately. If you perform a task difficulty assessing through the NASA-TLX, you can know reason about what is being affected. Through the effective management of the task difficulty level, in order to inhibit workload, it evaluates the task difficulty. Identifying efficient factor is very important, so more efficient management of the task difficulty level is possible.

\subsection{Previous Studies}

Many studies have compared touchscreens to other selection devices for various tasks Hall, Cunningham, Roache, and Cox (1988) investigated the effects of various factors on touchscreen performance. They reported that accuracy varied from $66.7 \%$ for targets $10 \mathrm{~mm}$ per side, to $99.2 \%$ for targets $26 \mathrm{~mm}$ per side, and that accuracy was maximized once targets were approximately $26 \mathrm{~mm}$ per side [6]. Ostroff and Shneiderman (1988) compared a touchscreen, mouse, number keys, and arrow keys. The results were similar to those of most other studies comparing the touchscreen and the mouse, indicating that the touchscreen was faster. They found no significant difference between error rates for the mouse and the touchscreen [7]. Ahlstrom and Lenman (1987) compared a conductive touchscreen and mouse for the selection. This study indicated that the touchscreen was faster, but resulted in a much higher error rate [8]. Karat, McDonald, and Anderson (1986) compared a touchscreen, mouse, and keyboard for selection tasks. The results indicated that the touchscreen was the preferred device for the task without the typing subtask, while the keyboard was preferred when the subtask was included. The touchscreen was the fastest for both tasks [9].

Table 1. Evaluation factors and description of NASA-TLX.

\begin{tabular}{cc}
\hline $\begin{array}{l}\text { Evaluation Factors } \\
\text { Mental Demand }\end{array}$ & Description \\
$\begin{array}{l}\text { Physical Demand } \\
\text { Temporal Demand }\end{array}$ & How physically demanding was the task? \\
Performance & How hurried or rushed was the pace of the task? \\
Effort & How hard did you have to work to accomplish your level or performance? \\
Frustration & How insecure, discouraged, irritated, stressed, and annoyed were you?
\end{tabular}




\section{Experiment Design}

\subsection{Experiment 1}

In this study, we have conducted experiments to maximize the operational capability as the operation in the GCS. Factors were set to lower display angle $\left(45^{\circ}, 60^{\circ}, 80^{\circ}\right)$ and input mode (Touch, Non Touch). In this regard, we measured the working time and the workload according to the factor by using the Flight Simulator $\mathrm{X}$ and to measure the workload, it was carried out NASA-TLX. (The baseline of NASA-TLX is $45^{\circ} /$ Non touch.) In Experiment 1,2 , both of the samples were determined 10.

In this experiment, including the Main Panel, Trim panel, Overhead Panel, Throttle Panel were used (see Figures 1 and 2).

Scenario is as follows.

1. Sequentially perform the setting for take-off on the GCS (As a given number). (Change the settings of 5 kinds at Main Panel, 2 kinds at Trim panel, 2 kinds at Overhead Panel, 4 kinds of Throttle Panel.)

2. Perform the take-off.

3. When climbed to a certain safe trajectory, perform the setting for normal flight (As a given number).

(Change the settings of 5 kinds at Main Panel, 2 kinds at Trim panel, 2 kinds at Overhead Panel, 4 kinds of Throttle Panel).

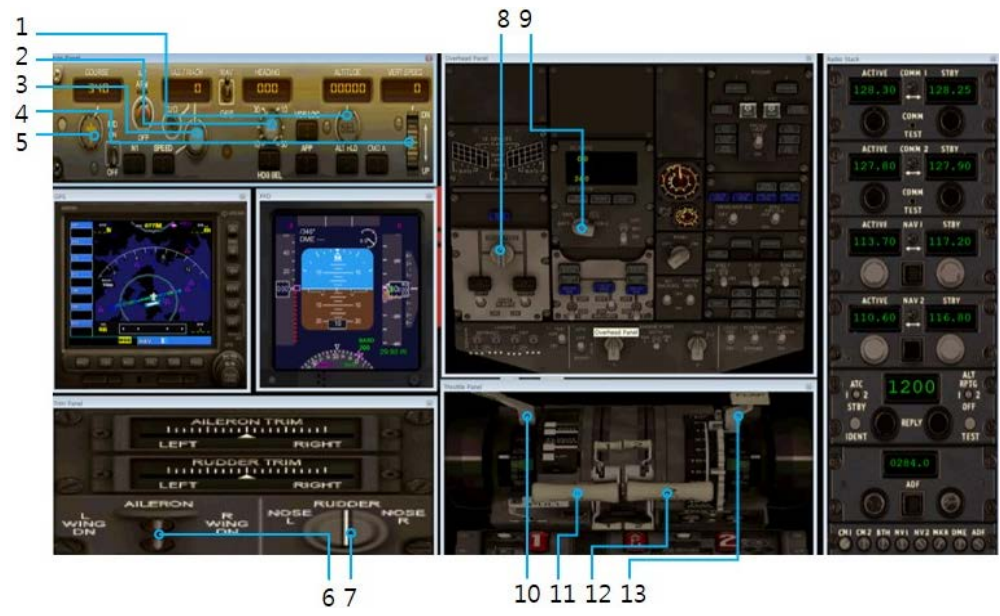

Figure 1. Interface of Experiment 1.

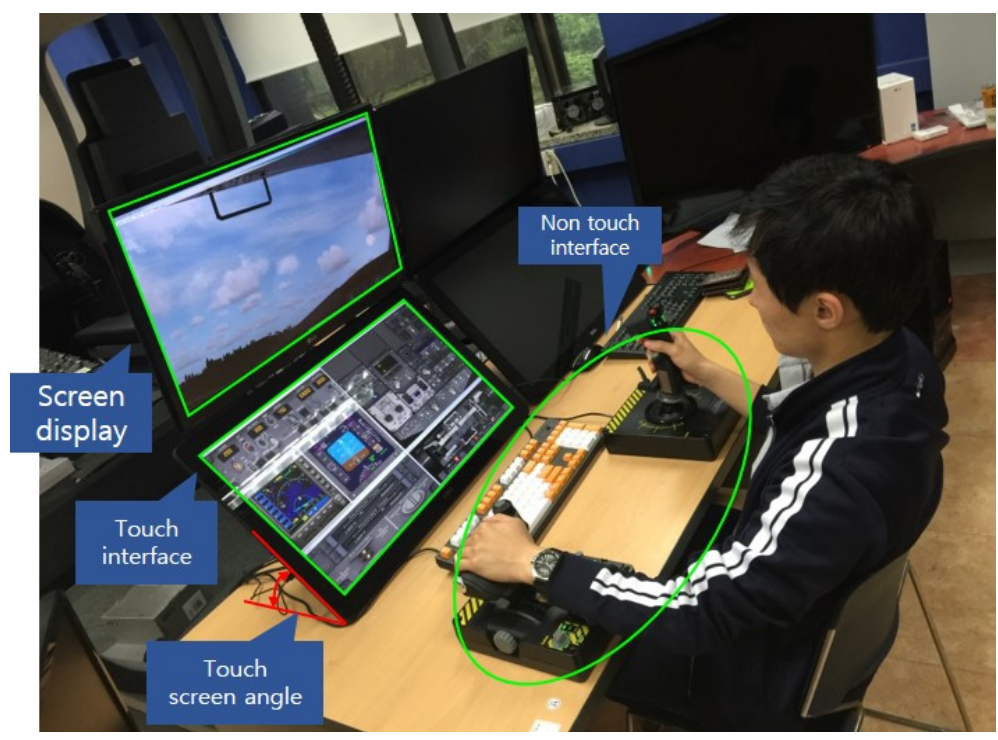

Figure 2. The example of Experiment 1. 


\subsection{Experiment 2}

Using the quantitative results obtained by experiments, it was performed ANOVA. The optimum lower display angle and input method according to the ANOVA were adopted (see Table 2). This experiment 2 was performed on the reaction rate and the workload measurement based. During GCS operating, we measured the reaction rate to a target is displayed at randomly (see Figure 3). We measured the workload by the NASA-TLX. Accordingly, we adopted optimum lower display angle and input mode in operating GCS. In Experiment 1, 2 both of the samples was determined 10.

\section{Result Analysis}

\subsection{Analysis of the NASA-TLX}

In Experiment 1, NASA-TLX showed that workload was optimal at lower display angle $60^{\circ}$, touch mode. Also, in significance level 0.05, $\mathrm{N}=10$. All of result about NASA-TLX was significant. (Mental Demand $(p=0.005)$, Physical Demand $(p=0.000)$, Temporal Demand $(p=0.014)$, Performance $(p=0.000)$, Effort $(p=0.000)$, Frustration $(p=0.006)$.) In Experiment 1, it was determined to be the most significant in $60^{\circ}$ angle (see Figure 4). And Experiment 2, the workload was measured according to the input mode in the $60^{\circ}$ angle (see Figure 5). Also, in significance level $0.05, \mathrm{~N}=10$. As a result, all of results are optimal at touch mode. Also like the previous Experiment 1, in significance level 0.05, all of result about NASA-TLX was significant (Mental Demand $(p=0.000)$, Physical Demand $(p=0.010)$, Temporal Demand $(p=0.002)$, Performance $(p=0.000)$, Effort $(p=$ $0.000)$, Frustration $(p=0.004))$.

\subsection{Analysis of the Working Time}

In Experiment 1, Also, in significance level $0.05, \mathrm{~N}=10$. Working time was optimal at $60^{\circ}$ angle and Touch mode. But, significant value is 0.928 . So, It showed that the results are not significant (see Figure 6). Because, Flight Simulator $\mathrm{X}$ is regarded as not being optimized for the touch screen, In Experiment 2, Also, in significance level $0.05, \mathrm{~N}=10$. the experiment was conducted in a different environment. As a result, Touch mode is faster than Non Touch mode. Also, significant value is 0.034 . So, the results were significant (see Figure 7).

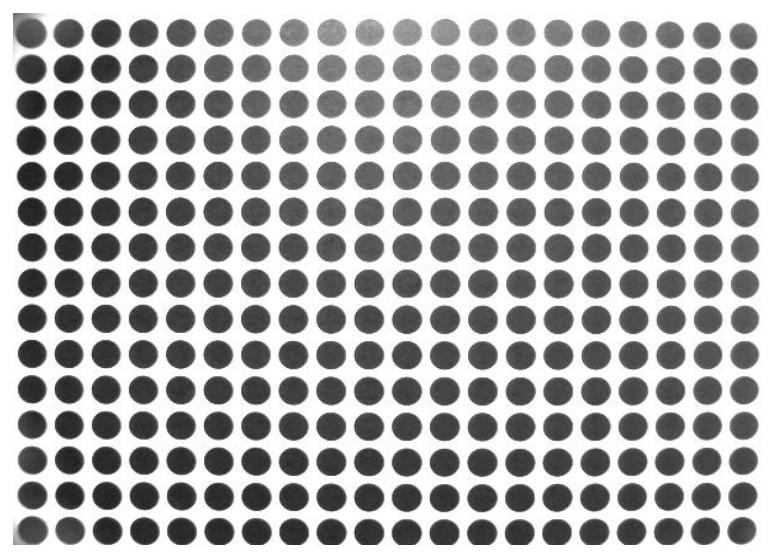

Figure 3. Interface of Experiment 2.

Table 2. Experiment design.

\begin{tabular}{ccc}
\hline \multirow{2}{*}{ Scale } & \multicolumn{2}{c}{ Input Mode } \\
\cline { 2 - 3 } & Non Touch & Touch \\
\hline Lower Display angle & $45^{\circ}, 60^{\circ}, 80^{\circ}$ & $45^{\circ}, 60^{\circ}, 80^{\circ}$ \\
Time & Measured in Seconds & Measured in Seconds \\
NASA-TLX & Rating from given 6 questions & Rating from given 6 questions \\
$(100$ points range with 5-point steps $)$ & $(100$ points range with 5-point steps $)$ \\
\hline
\end{tabular}




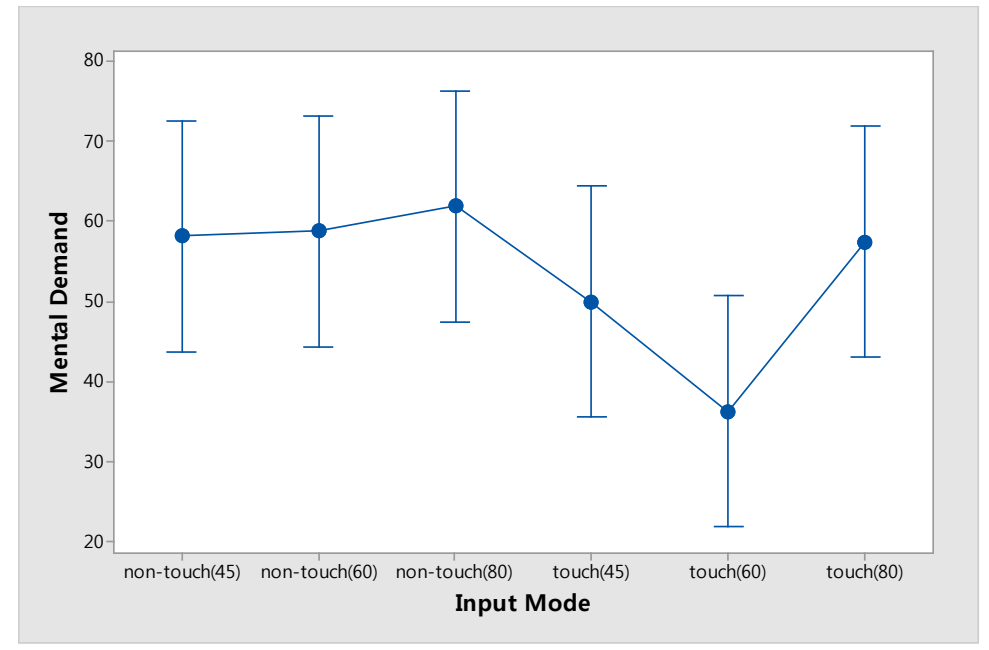

Figure 4. NASA-TLX according to input mode (in Experiment 1).

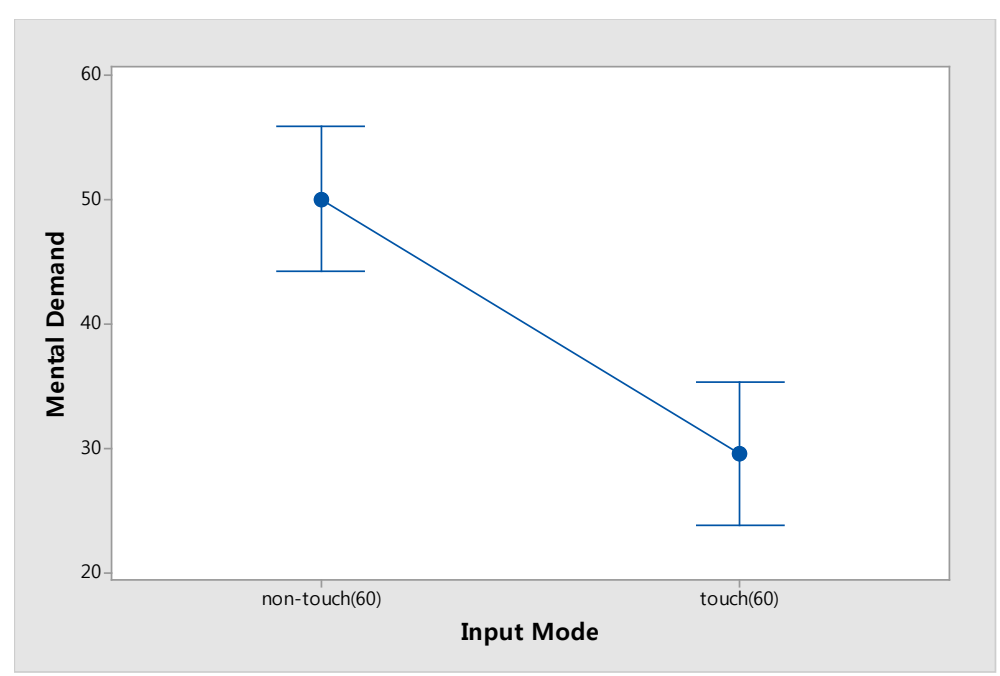

Figure 5. NASA-TLX according to input mode (in Experiment 2).

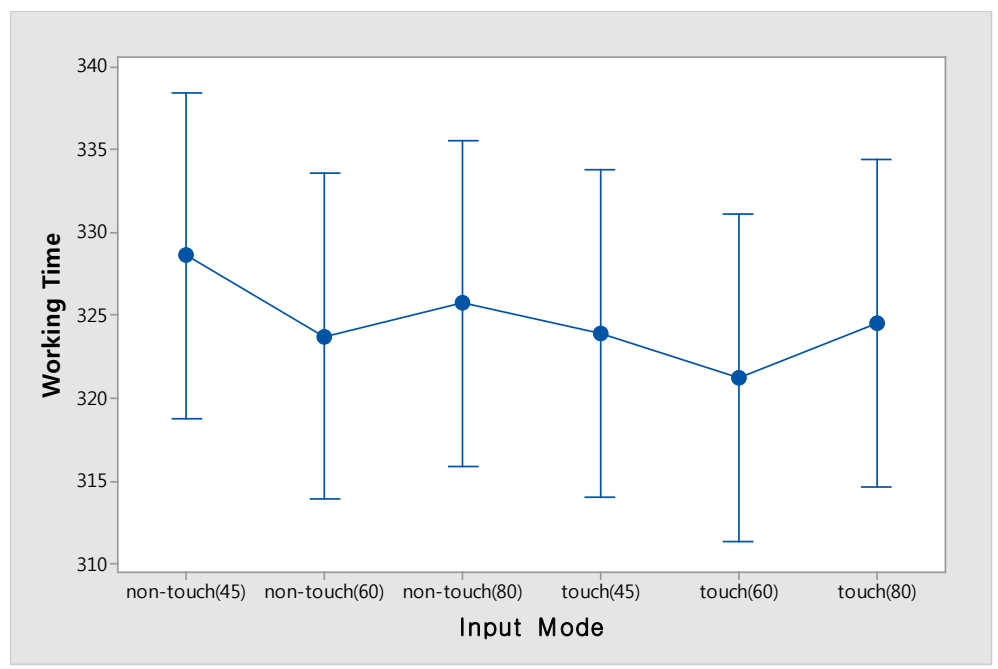

Figure 6. Working time according to input mode (in Experiment 1). 


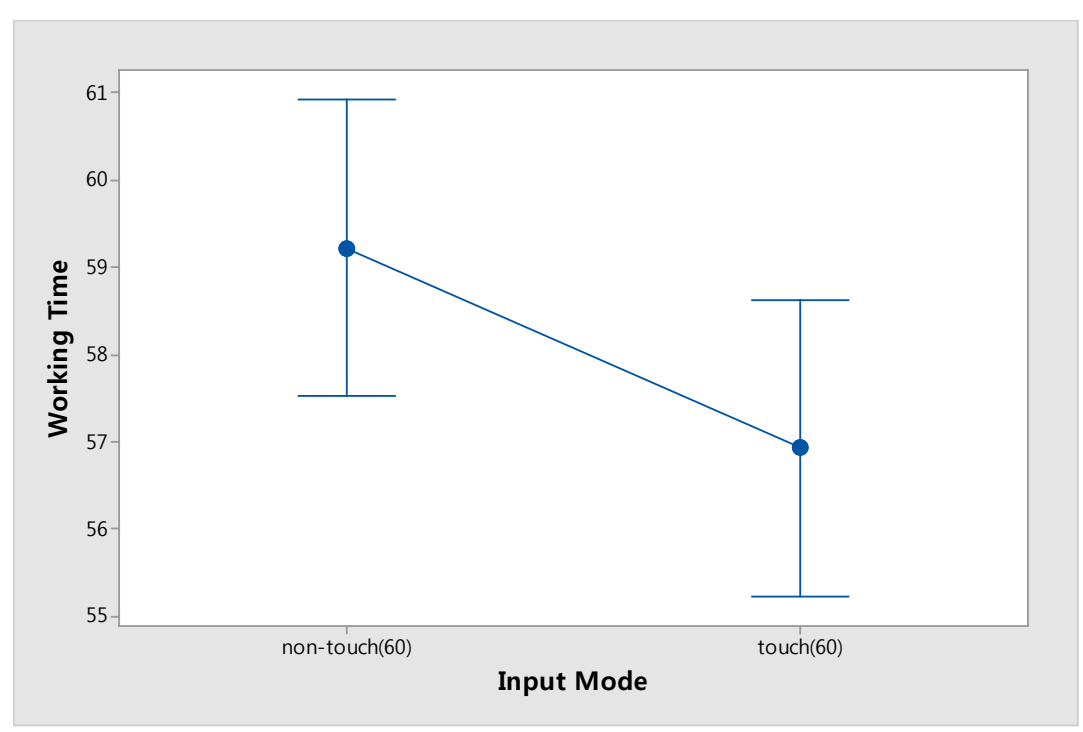

Figure 7. Working time according to input mode (in Experiment 2).

\section{Conclusion}

As a result, in Experiment 1, it was found that Touch mode was the best results of $60^{\circ}$ angle. Also, in Non Touch mode, $80^{\circ}$ angle is optimal but, in NASA-TLX, Touch mode is far more efficient than Non Touch mode. Therefore, it was found that Touch mode is optimal and in Touch mode, $60^{\circ}$ angle is optimal. But, Flight Simulator $\mathrm{X}$ using in Experiment 1 is regarded as not being optimized for the touch screen, the significance level showed that the working speed is not significant. So, secondarily we performed different experiment about working speed and workload. In different experiment, it was found that touch mode is faster than Non Touch mode. As a result, we conclude that Touch mode is more optimal about working speed and workload.

\section{Acknowledgements}

This work was supported by the Agency for Defense Development (ADD) under the Contract No.

UD140066CD. The authors wish to express sincere gratitude for the financial support.

\section{References}

[1] Hart, S.G. and Staveland, L.E. (1988) Development of NASA-TLX (Task Load Index): Results of Empirical and Theoretical Research. In: Hancock, P.A. and Meshkati, N., Eds., Human Mental Workload, Elsevier Science Publisher B. V., North-Holland, 139-183. http://dx.doi.org/10.1016/s0166-4115(08)62386-9

[2] Campbell, D.J. and Gingrich, K.F. (1986) The Interactive Effects of Task Complexity and Participation on Task Performance: A Field Experiment. Organizational Behavior and Human Decision Processes, 38, 162-180. http://dx.doi.org/10.1016/0749-5978(86)90014-2

[3] Woods, D.D. (1990) On Taking Human Performance Seriously in Risk Analysis: Comments on Dougherty. Reliability Engineering and System Safety, 29, 375-381. http://dx.doi.org/10.1016/0951-8320(90)90022-F

[4] Miyake, S. (2001) Multivariate Workload Evaluation Combining Physiological and Subjective Measures. International Journal of Psychophysiology, 40, 233-238. http://dx.doi.org/10.1016/S0167-8760(00)00191-4

[5] Hill, S.G., Iavecchia, H.P., Byers, J.C., Bittner, Jr., A.C., Zaklad, A.L. and Christ, R.E. (1992) Comparison of Four Subjective Workload Rating Scale. Human Factors, 24, 429-439.

[6] Hall, A., Cunningham, J., Roache, R. and Cox, J. (1988) Factors Affecting Performance Using Touchentry Systems: Tactal Recognition Fields and System Accuracy. Journal of Applied Psychology, 73, 711-720. http://dx.doi.org/10.1037/0021-9010.73.4.711

[7] Ostroff, D. and Shneiderman, B. (1988) Selection Devices for User of an Electronic Encyclopedia: An Empirical Comparison of Four Possibilities. Information Processing \& Management, 24, 665-680. http://dx.doi.org/10.1016/0306-4573(88)90004-0 
[8] Ahlstrom, B. and Lenman, S. (1987) Touch Screen, Cursor Keys, and Mouse Interaction. Work with Display Units, Elsevier, North-Holland, 831-837.

[9] Karat, J., McDonald, J. and Anderson, M. (1986) A Comparison of Selection Techniques: Touch Panel, Mouse, Keyboard. International Journal of Man-Machine Studies, 1, 73-92. http://dx.doi.org/10.1016/S0020-7373(86)80034-7 